\title{
Efficient Production of Solar Fuel Using Existing Large Scale Production Technologies
}

\author{
W. Haije ${ }^{t, t}$ \\ H. Geerlings ${ }^{\dagger, \S}$ \\ †Department of Chemical Engineering, Delft University of Technology, Julianalaan 136, 2628 BL Delft, The Netherlands \\ łEnergy research Centre of The Netherlands, PO BOX 1, 1755 ZG, Petten, The Netherlands \\ §Shell Global Solutions International B.V., Grasweg 31, 1031 HW Amsterdam, The Netherlands
}

Published in Environ. Sci. Technol. 2011, 45, 8609-8610 


\title{
Efficient Production of Solar Fuel Using Existing Large Scale Production Technologies
}

\author{
Wim Haije $\mathrm{e}^{*,+, \neq}$ and Hans Geerlings ${ }^{+, \S}$ \\ ${ }^{\dagger}$ Department of Chemical Engineering, Delft University of Technology, Julianalaan 136, 2628 BL Delft, The Netherlands \\ ${ }^{\ddagger}$ Energy research Centre of The Netherlands, PO BOX 1, 1755 ZG, Petten, The Netherlands \\ ${ }^{\S}$ Shell Global Solutions International B.V., Grasweg 31, 1031 HW Amsterdam, The Netherlands
}

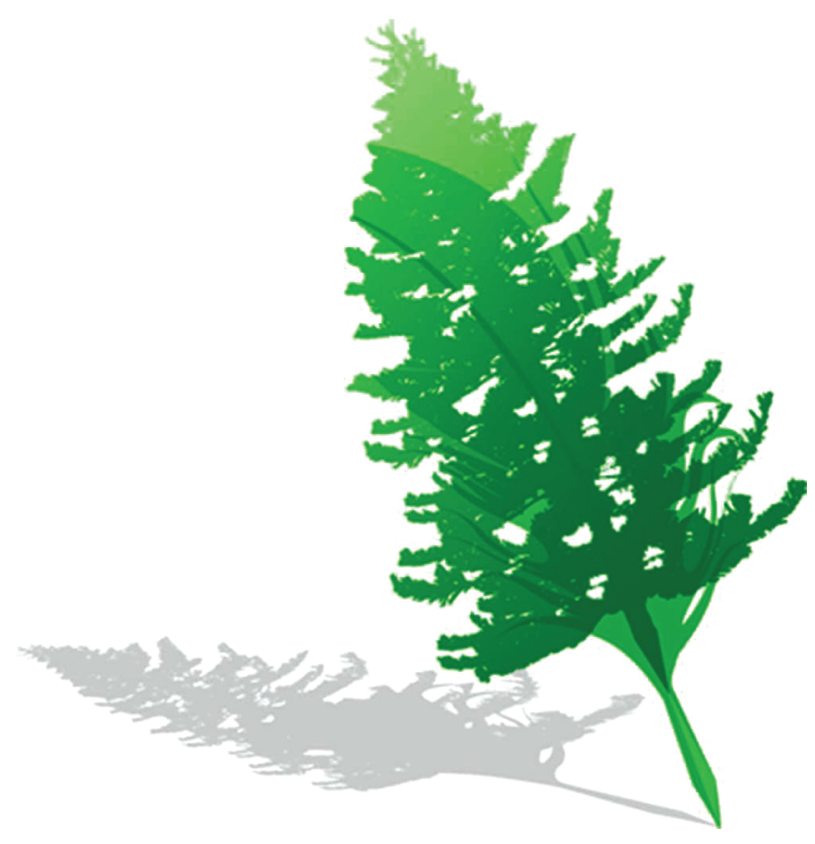

\section{INTRODUCTION}

Global energy consumption will at least double during this century. Today about $80 \%$ of the primary energy used is provided by fossil fuels. To avoid anthropogenic climate change, it is essential that the world's energy system is gradually transformed from fossil energy based to a solar based one. In such a solar world, efficient energy storage is prerequisite to deal with the intermittency of this abundant source. Storage in the form of chemical energy, that is, solar fuels, provides a natural route to deal with this problem. An obvious solar fuel would be hydrogen, which can be produced efficiently from solar energy through direct splitting of water or through combination of solar electricity production with electrolysis of water. ${ }^{1}$ Unfortunately, hydrogen has a major disadvantage as its transport and storage is not trivial. No such storage problem exists for alcohols or liquid hydrocarbons. Especially liquid hydrocarbons are preferred solar fuels in view of their unprecedented combination of gravimetric and volumetric energy density and the worldwide existing markets and infrastructure.

\section{SOLUTION}

Though hydrogen is not the ideal solar fuel, it is a very attractive intermediate as liquid hydrocarbons can be produced through hydrogenation of $\mathrm{CO}_{2}$. The $\mathrm{CO}_{2}$ is captured at fossil fuel based power plants or directly from the air. To produce liquid hydrocarbon fuels from solar hydrogen and $\mathrm{CO}_{2}$, the reverse water-gas shift reaction (RWGS):

$$
\mathrm{H}_{2}+\mathrm{CO}_{2} \leftrightarrow \mathrm{CO}+\mathrm{H}_{2} \mathrm{O} \Delta \mathrm{H}_{0}=+41 \mathrm{~kJ} / \mathrm{mol}
$$

combined with commercial cobalt based Fischer-Tropsch technology is the obvious route. Figure 1 gives an artist impression of this solar fuels scheme. With the exception of the RWGS process the whole process train is already available on a (sub)commercial scale today. The RWGS is an endothermic equilibrium reaction, and the equilibrium lies on the product side only for temperatures above $800{ }^{\circ} \mathrm{C}$. The conversion at lower temperatures, $150-250{ }^{\circ} \mathrm{C}$ can be enhanced greatly, up to $100 \%$, if a reaction product, that is, water, is selectively removed. At laboratory scale Carvill et al. ${ }^{2}$ showed that even pure $\mathrm{CO}$ could be produced at $250{ }^{\circ} \mathrm{C}$ in a sorbent enhanced RWGS (SERWGS) process. In the current solar fuels process it suffices if the SERWGS step produces a mixture of $\mathrm{CO}$ and hydrogen (synthesis gas). The inset in figure 1 shows a typical experimental result. In this case $\mathrm{CO}_{2}$ and hydrogen are fed to a fixed bed reactor, which contains a mixture of a low temperature WGS catalyst (SüdChemie) and a water sorbent (for our experiments molsieve 4A (Merck)). Initially essentially complete conversion of $\mathrm{CO}_{2}$ is obtained. After saturation of the sorbent, breakthrough of $\mathrm{CO}_{2}$ occurs and the conversion converges toward chemical equilibrium.

In practice the SERWGS process is also executed in a fixed bed reactor, which contains a mixture of a watergas shift catalyst and a sorbent. Saturation of the sorbent with water necessitates a number of parallel reactors: one reactor is producing synthesis gas, while the others are in various stages of regeneration. This configuration is similar to that of the sorbent enhanced water-gas shift process, SEWGS, currently under development. ${ }^{3}$ No major hurdles are therefore foreseen for further development of the SERWGS process. The heat released by the sorption reaction is sufficient to drive the RWGS reaction. The heat released by the exothermic Fischer-Tropsch process $(-160 \mathrm{~kJ} / \mathrm{mol})$ can subsequently be used to fully regenerate the water sorbent $(55 \mathrm{~kJ} / \mathrm{mol})$, optimizing the sustainability of the process.

To obtain an estimate of the efficiency from solar energy to liquid fuels one can multiply the efficiency of the various subprocesses. State-of-the-art photovoltaic panels achieve efficiencies of

Received: September 9, 2011

Accepted: September 12, 2011

Published: September 21, 2011 


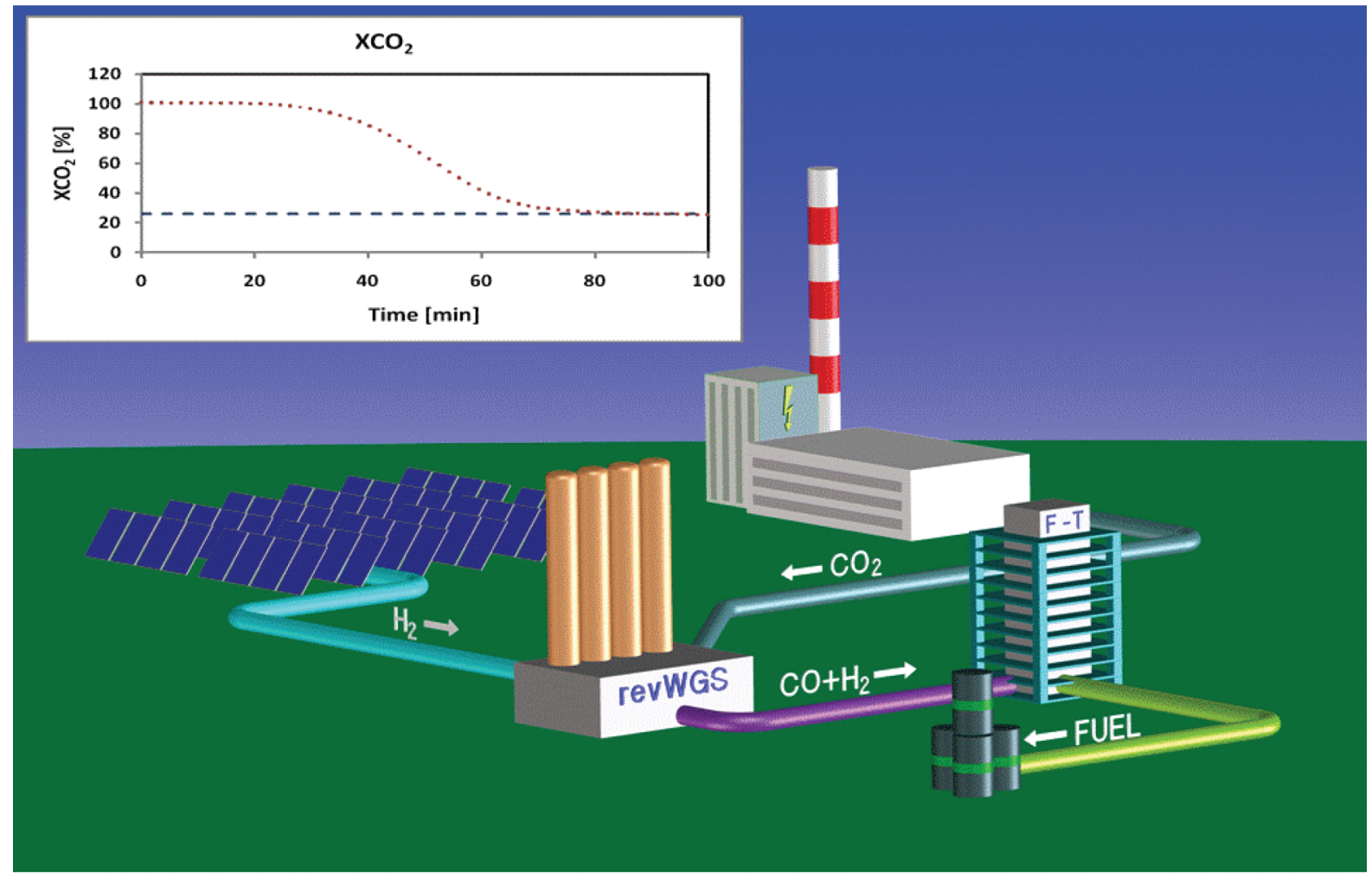

Figure 1. An artist impression of a solar fuels process. Liquid hydrocarbon fuels are produced from solar hydrogen and $\mathrm{CO}_{2}$. Inset shows experimental conversion of $\mathrm{CO}_{2}$ as a function of time in the SERWGS reaction $\left(p=1 \mathrm{bar}, \mathrm{T}=300{ }^{\circ} \mathrm{C}, \mathrm{H}_{2} / \mathrm{CO}_{2}\right.$ feed ratio $=4$, GHSV $=170 \mathrm{~h}{ }^{-1}$, equilibrium conversion: horizontal dashed line).

19\%. The efficiency of high pressure electrolysis is about $85 \%$, which implies that solar hydrogen can be produced with efficiencies around $16 \%$. Including a mismatch between photovoltage and electrolysis potential this number reduces to $13 \%$. ${ }^{1}$ The efficiency of the SERWGS and Fischer-Tropsch steps are estimated to be of the order of $90 \%$ and $70 \%$ respectively. This yields an overall efficiency from solar energy to liquid fuels of about $8.2 \%$. This number is not very sensitive to inclusion of the energy penalty connected with $\mathrm{CO}_{2}$ capture. A realistic energy penalty of $150 \mathrm{~kJ} / \mathrm{mol}$ of $\mathrm{CO}_{2}$ reduces the efficiency of solar fuel synthesis to $7.7 \%$.

This number compares favorably with efficiencies reported for a number of alternative routes to produce solar fuels including advanced biomass conversion, artificial photosynthesis and thermochemical production. ${ }^{4}$ Many of these technologies, though promising in the long term, are still in a rather early stage of their development and the efficiencies from solar energy to chemical energy are still low, typically below $1 \%$.

\section{SUMMARY}

Solar fuels can be produced efficiently already today using existing technologies. Liquid hydrocarbon fuels production from $\mathrm{CO}_{2}$ and water with efficiencies approaching $10 \%$-from solar energy to fuel-is feasible. This is about an order of magnitude higher than alternative technologies currently under development. The main challenge for further research is to reduce costs and further improve efficiency through optimized process schemes. The main challenge for further research is to reduce costs and further improve efficiency through optimized process schemes and PV systems.

\section{AUTHOR INFORMATION}

\section{Corresponding Author}

*E-mail: haije@ecn.nl .

\section{REFERENCES}

(1) Blankenship, R. E.; et al. Science 2011, 332, 805-809.

(2) Carvill, B. T; Hufton, J. R.; Anand, M.; Sircar, S. Sorptionenhanced reaction process. AIChE J. 1996, 42, 2765.

(3) E. R. Van Selow et al., Pilot-scale development of the sorption enhanced water gas shift process. In Carbon dioxide Capture for Storage in Deep Geologic Formations; E. Li, Ed.; Berks CPL Press, 2009, p 157.

(4) Somnath, R. C.; Varghese, O. K.; Paulose, M.; Grimes; Craig, A. Toward solar fuels: Photocatalytic conversion of carbon dioxide to hydrocarbons. ACS Nano 2010, 4 (3), 1259-1278. 